\title{
Sociología moral del dinero en el mundo popular
}

\author{
Ariel Wilkis \\ CONICET, Universidad Nacional de San Martín, \\ Universidad Nacional del Litoral \\ ariel.wilkis@gmail.com
}

\section{Resumen}

Este artículo analiza la conformación de una nueva infraestructura monetaria del mundo popular. Muestra el rol creciente del dinero en estos sectores y se pregunta sobre las nuevas formas de integración social que estos cambios suponen. Aborda estos cambios desde una sociología moral del dinero. Utiliza materiales empíricos de un trabajo de campo en las barriadas de la periferia de la Ciudad de Buenos Aires entre 2006 y 2010.

Palabras clave: dinero, moral, clases populares, sociología económica.

\section{Abstract}

\section{Moral sociology of money in the life of poor}

This article analyzes the conformation of a new monetary infrastructure in the life of poor. It shows the increasing role of the money in these sectors and the new forms of social integration that these changes suppose. It approaches these changes from a moral sociology of money. It uses empirical materials of a fieldwork in the slums of the City of Buenos Aires between 2006 and 2010.

Key words: money, morality, poor people, economic sociology. 


\section{Introducción}

Conocí a Mary durante mi trabajo de campo en una "villa" de La Matanza (Wilkis, 2013). Tenía 58 años y vivía hace 25 en Villa Olimpia. Su casa actual, menos precaria que la anterior, presentaba igualmente un sinfín de problemas por la falta de agua corriente, de cloacas y de un techo que evitara las filtraciones. Cada noche antes de dormir, Mary hacía sumas y restas. En esos pequeños montos de dinero, en esos cálculos de escala minúscula, concentraba su deseo y su imaginación para mejorar un presupuesto que permanecía en déficit permanente.

Mary imaginaba nuevas fuentes de ganancias. Pensaba visitar la feria de La Salada para comprar ropa a precios módicos y luego revenderla más cara. Muchos vecinos de la villa prefieren quedarse en sus casas antes que trasladarse al gigantesco mercado popular desplegado sobre la vera del río más contaminado de la región. Se calcula que unas 150 mil personas van a la feria cada una de las dos noches por semana que abre. Muchos arriban desde países limítrofes, desde ciudades grandes o pequeñas del país o desde el conurbano; luego retornan a sus lugares y revenden lo que compraron.

Mary también imaginaba cómo aumentar ese dinero ganado mejorando su venta de bebidas y alimentos todos los fines de semana en la cancha de fútbol de la villa. El próximo verano invertiría en una heladera nueva. Sabía cómo: le pedirá a su comadre, titular de una tarjeta en una cadena minorista de electrodomésticos, que le saque un crédito. Ella le pagaría en cuotas. Hace tiempo ya que Mary sabe que puede contar con ese recurso y se le ha tornado una costumbre usarlo, al igual que hacen gran parte de las familias del barrio. Este deseo señala el lugar que ocupan las grandes cadenas de comercios, los bancos, las agencias financieras y las compañías de tarjetas en la realidad material y simbólica de las clases populares. La economía popular se ha financiarizado (Wilkis, 2014a).

Cuando sus hijos llegaban del frigorífico donde trabajaban, sacaban de un bolso unos cuantos kilos de carne. Antes de cambiarse la ropa manchada

${ }^{1}$ Los primeros asentamientos de este estilo en la ciudad de Buenos Aires datan de la década del treinta, por el peso de la crisis económica y las migraciones internas hacia la ciudad de Buenos Aires, centro económico y político del país. En las décadas siguientes la población de estos territorios de relegación urbana y social se expandió, alimentada tanto por la continuación de las mudanzas internas como por la inmigración de los países limítrofes. En 1981 representaba $4.3 \%$ de la población total del conurbano; en $1991,5.2 \%$; en $2001,6.9 \%$ y en $2006,10.1 \%$ (Cravino, Del Río y Duarte, 2009). En 1991 habitaban villas y asentamientos 22655 matanceros, que representaba $2 \%$ de la población del municipio; en 2001 llegaban a $69157,5.5 \%$ del total (Cravino, 2007). Las estadísticas en villas y en asentamientos muestran los niveles más elevados de desempleo, pobreza, trabajo informal, incidencia de planes sociales, etcétera. 
de sangre, preparaban varios paquetes pequeños en fracciones; poco tardaban en llegar los clientes, que negociaban la cantidad de dinero que pagarían por cada envoltorio. El dinero y la carne se intercambiaban bajo la mirada atenta de Mary. Una vez finalizadas las ventas, les pedía a sus hijos una parte de lo recaudado. "Ellos saben que me tienen que dar el dinero, iyo pongo también!", me decía en guaraní primero y, luego, lo traducía al español. Para ella, la fuerza y unidad de su familia descansa en este principio de equidad distributiva. El dinero, piensa y siente Mary, debe ser cuidado; sólo así se protege a la familia.

Mary tenía un "trabajo político": visitaba las casas de sus vecinos y les resolvía problemas en nombre de Salcedo, el líder político del barrio. También los invitaba a algún acto o movilización al centro de la ciudad de Buenos Aires. Ella recibía un sueldo por su trabajo de militante, "un sueldo político", aclaraba. Este dinero militado tiene dos tiempos: el de la expectativa de recibirlo, que es constante, y el del monto y el día del pago, que varían.

"Decile que te pague", le aconsejaba el párroco del barrio, desde el lugar de quien sabe cómo administrar el dinero en un contexto que mezcla necesidades materiales, cuestiones políticas y afectos. Las donaciones monetarias llegan a su parroquia como un gesto de solidaridad con su obra: las empresas de la zona o algún político en ascenso proveen el dinero donado. Algunas personas cobraban por hacer tareas de limpieza; pero las mujeres del barrio más próximas al párroco no recibían nada, son "voluntarias": ellas encarnan el dinero sacrificado.

Mary aguarda y renueva sus esperanzas. Las madres de sus nietos han empezado a cobrar las becas de ayuda escolar del gobierno; su hijo menor ha ingresado a un plan social para trabajar en una cooperativa de construcción. Los programas de transferencias monetarias condicionadas se habían convertido en el paradigma de política social en todos los países de América Latina (Lavinas, 2013). El dinero llega a las familias a través del Estado, bajo planes diseñados por expertos de organismos internacionales como el Banco Interamericano de Desarrollo o el Banco Mundial.

Quisiera llamar la atención sobre lo siguiente: difícilmente se podría narrar la vida cotidiana de Mary y su familia si dejamos de lado la relación que mantiene con el dinero. ¿Cómo comprenderíamos muchos de sus sufrimientos, su angustia, sus ilusiones, sus esperanzas? Al excluir el dinero de la narración, una porción del mundo de los sentimientos y afectos de Mary quedaría oculta y silenciada.

En la dimensión colectiva, la exclusión del dinero también plantearía importantes interrogantes: ¿cómo podríamos hablar de la economía barrial 
y sus conexiones con universos mercantiles como las ferias populares o las grandes tiendas? ¿O bucear en el interior de las redes políticas?

Según sugieren estas preguntas, tomar en cuenta el dinero no sólo nos garantiza darle expresión y visibilidad a parte de los afectos y sentimientos de Mary, sino que, además, nos permite conectar su experiencia personal con las dinámicas sociales, económicas y políticas en las que está inmersa. En pocas palabras, el dinero nos ayuda a descifrar cómo es su vida colectiva.

En los últimos tiempos, un número creciente de antropólogos y sociólogos latinoamericanos han puesto la lupa en los vínculos y significados sociales del dinero en el mundo popular.

Federico Neiburg (2011) nos invita a comprender cómo funcionan las monedas imaginarias que enhebran las ganancias en los mercados haitianos. Pascale Absi (2007) analiza las estrategias monetarias de las comerciantes indígenas bolivianas. El dinero nos transporta, también, por las actividades religiosas: la expansión de grupos pentecostales le dio otra visibilidad al dinero, que Diana Nogueira de Oliveira Lima (2008) explora en Brasil y Francesco Zanotelli (2005) en el mundo católico de México. Y por los dramas familiares que producen las deudas, los divorcios y las herencias: Lúcia Müller desglosa los procesos de endeudamiento en las familias populares del sur de Brasil (2009); Magdalena Villarreal (2009) reconstruye las tensiones cuando las deudas pautan la vida de las familias pobres rurales de México; Taylor Nelms (2012) da voz a los comerciantes endeudados de los mercados populares de Quito; Macarena Barrios (2011) cuenta las presiones financieras sobre los hogares de bajos recursos de Santiago de Chile. Y hasta por el juego: tanto la quiniela como el bingo o el juego de cartas ocupan cada vez más tiempo y dinero, según muestran DaMatta y Soárez (1999), Fernando Rabossi (2011) y Pablo Figueiro (2012), quienes revelan cómo éste anima la sociabilidad popular, ya sea en el jogo do bicho, en el chichon entre vendedores callejeros de Foz de Iguazú, o en las apuestas de una agencia de quiniela de la periferia de Buenos Aires. Gabriel Kessler (2013) explora sus sentidos para los jóvenes de los barrios marginales inmersos en la economía del delito.

Vemos el dinero circular en relaciones mercantiles, políticas, religiosas, familiares, amorosas, ilícitas y lúdicas. Estos trabajos nos ayudan a percibir que el dinero ocupa un lugar central en la vida colectiva y personal de estos sectores. Dinámicas transnacionales con fuertes efectos locales como la globalización de mercancías (Pinheiro-Machado, 2011), la financiarización del consumo (Ossandon, 2011), o la monetización de los programas sociales (Hornes, 2013; Eger, 2012) son procesos que también ponen el dinero en el centro de la vida popular. 
Historias como las de Mary y su familia, y este creciente interés en la sociología y antropología, me llevan a proponer lo siguiente: una nueva infraestructura monetaria del mundo popular se fue gestando y desarrollando en los últimos años.

Algunos procesos, que ya mencioné, producen esta configuración que, para hablar como Norbert Elias, cambia el equilibrio de poder en el mundo popular: la monetización de la política social (cada vez la asistencia social se desarrolla a través de transferencias condicionadas de dinero); la financiarización del consumo popular (se observa una oferta extendida y diversificada de instrumentos de crédito para el consumo entre los sectores de menores ingresos); la extensión de nuevas redes de comercialización informal con nodos en mercados populares como La Salada en Buenos Aires, Tepito en México, El Alto en La Paz; la redefinición en el universo del marketing y de las empresas del lugar relevante que tienen los sectores de la "base de la pirámide" como agentes en el mercado; finalmente, la consideración por parte de algunos gobiernos de la región del "consumo popular" como indicador de desempeño positivo tanto económico como social de las políticas estatales.

Esta mutación supone algunos desafíos para la sociología y antropología del mundo popular. En este artículo me interesa responder las siguientes preguntas: ¿qué sucede cuando la vida popular se vuelve más monetaria? Cuando el dinero se presenta cada vez más en los intercambios políticos, sociales, económicos, afectivos, ¿se individualizan las relaciones sociales? ¿Las personas se autonomizan de sus compromisos, lealtades y obligaciones? Un interrogante más específico: ¿La interpretación de las culturas populares a través de la noción de jerarquía (Duarte, 2004) perdería valor frente a la generalización monetaria que tendría un poder individualizante?

La descripción de esta mutación y las preguntas que surgen de su interpretación se asemeja a procesos ya tratados por la literatura especializada en sociología y antropología económica. Quienes apuestan a mostrar la dimensión abstracta e impersonal del dinero, sugieren que los procesos de generalización monetaria erosionan los valores morales (Bohannan, 1959). Quienes apuestan a mostrar la heterogeneidad de sus significados y sus usos, indican que la generalización monetaria produce una rica variedad de conexiones morales (Zelizer, 1994).

Mi posición se ubica más próxima a esta segunda variante. Como bien lo pone en consideración Viviana Zelizer (1994), no conviene considerar el dinero como una variable independiente de un proceso que se quiere explicar: su crecimiento cuantitativo no da razón por sí mismo de su papel en la vida social. Si lo tratamos como un dato aislado, tendemos a verlo de manera homogénea, como si produjera los mismos efectos en contextos diferentes. 
Me propongo en este artículo presentar la perspectiva de la sociología moral del dinero que provee los instrumentos para responder las preguntas arriba formuladas. El plan del artículo es el siguiente: en la primera parte me concentro en desarrollar las líneas conceptuales de la sociología moral del dinero. Destaco cómo esta perspectiva se relaciona con los desarrollos de una "nueva" sociología moral y con la agenda de la sociología económica. En la segunda parte del artículo me interesa mostrar el aporte de esta perspectiva para analizar la nueva infraestructura monetaria del mundo popular. En primer lugar, presento cómo la sociología moral del dinero se diferencia de las interpretaciones más habituales sobre la economía popular. En segundo lugar, muestro por qué hoy día esta perspectiva es necesaria frente a una nueva infraestructura monetaria. En tercer lugar, propongo la sociología moral del dinero cómo una vía para comprender las dinámicas de jerarquización en el mundo popular.

\section{Un esbozo de sociología moral del dinero}

La economía define cuatro funciones centrales del dinero:

1) Ser un medio de pago.

2) Operar como unidad de cuenta.

3) Ser una reserva de valor.

4) Ser un medio de intercambio.

Estas funciones describen una institución destinada a organizar transacciones económicas. Históricamente se ha preferido aceptar las expectativas cifradas en su dimensión organizativa. Sin embargo, las nuevas interpretaciones antropológicas y sociológicas que exploraron el dinero le dieron una entidad menos instrumental y neutral, y más experiencial y sensible a sus usos y circulaciones. ${ }^{2}$

Viviana Zelizer ha forjado instrumentos de conocimiento cruciales para esta perspectiva. Lejos de adoptar un enfoque homogéneo, concentrado en un mismo uso y significado, su lectura rompe el molde que encorseta la interpretación sobre el dinero. La pluralidad de significaciones del dinero (Zelizer, 1994) es un pista en ese sentido. Una ruptura en el mismo sentido produce otros trabajos (Bloch y Parry, 1989; Hart, 2000; Guyer, 2004).

\footnotetext{
${ }^{2}$ Se pueden consultar varios textos sobre el estado de esta literatura: Maurer (2006), Dufy y Weber (2009) [2007], Blanc (2009), Carruthers y Ariovich (2010).
} 
Partiendo del sustrato de estas producciones, Bill Maurer (2006) sugiere pensar que lo central del dinero es la tensión que yace en el corazón de sus representaciones, porque ninguna captura totalmente su significado: siempre queda un desborde que restituye su heterogeneidad. Su tesis sostiene que el dinero existe en la vida social debido a sus propios desperfectos, aquellos que se originan entre las representaciones y los usos que se le dan.

Siguiendo esta reflexión, la sociología del dinero que propongo captura estos desperfectos a partir de las dinámicas morales que los hechos monetarios exponen a las personas y sus vínculos sociales. Para especificar esta perspectiva quisiera, primero, ubicar mi trabajo en relación con los desarrollos recientes de lo que se ha denominado una nueva sociología moral (Hitlin y Vaisey, 2010); posteriormente integraré esta posición en el campo de los estudios sociales de la economía y el dinero.

\section{El capital moral y una nueva agenda sociológica}

La sociología ha establecido una relación privilegiada con los hechos y actos morales. Las indagaciones de Durkheim por homologar hechos morales y hechos sociales, la preocupación weberiana sobre el mundo de los valores, la teoría de las tres obligaciones de la circulación del don de Mauss, los desarrollos de Parsons y Merton sobre la integración normativa o la anomia, el orden, la interacción goffmiano y su carácter sagrado, el mantenimiento de las expectativas normativas de Garfinkel, los emprendedores morales de Becker, la ética del honor de Bourdieu y, más recientemente, la sociología de la justificación pública de Bolstanki y Thévenot, informan una historia subdisciplinar específica hilvanada por la preocupación sobre la moralidad de los vínculos sociales.

Pese a la aparente persistencia a lo largo de la historia de la disciplina, esta preocupación tiene momentos de mayor auge y de decline. Patrick Pharo (2004) ha historizado para el caso francés estos ciclos, indicando el auge de la sociología moral en las últimas dos décadas luego de un ostracismo atribuido al dominio del marxismo o enfoques históricos políticos. Otras disciplinas, como la antropología, también han experimentado este renacer (Fassin, 2012). Hitlin y Vaisey (2010) también ponen en perspectiva histórica este renovado interés en la sociología anglosajona. En esta renovación hay una clara preocupación por construir una agenda lo más desprovista de componentes normativos y orientada a desplegar medios conceptuales que identifiquen contextualmente dinámicas morales. Hitlin y Vaisey ex- 
ponen los puntos cruciales que organizan la emergente sociología moral. Éstos son:

1. Vincular las dinámicas morales con el acceso a recursos y al poder.

2. Tomar en cuenta la complejidad de los significados morales que se atribuyen a personas, acciones, sucesos, etcétera.

3. Conectar contextos sociohistóricos y dinámicas morales.

En este artículo sugiero considerar el concepto de capital moral como un medio conceptual apto para lograr esta triple exigencia de una nueva sociología moral.

En la obra de Pierre Bourdieu, el desarrollo del concepto de capital simbólico derivó en un programa de investigación en torno a todas las formas de reconocimiento que otorgan poder y legitimidad (Wilkis, 2014b). Las diversas subespecies de capital simbólico especifican diferentes tipos de reconocimiento. Por ejemplo, el capital agonístico (Mauger, 2006) reconoce la habilidad en el uso de la violencia física. El capital erótico (Hakim, 2010) reconoce las destrezas de la seducción. El concepto de capital moral también es una subespecie del capital simbólico.

Las personas miden, comparan y evalúan todo el tiempo sus virtudes morales. Poseer capital moral es ser reconocido a través de estas virtudes. Por ejemplo, el cumplimiento de obligaciones puede ser una fuente de estos reconocimientos (Mauss, 1971). El concepto de capital moral identifica este tipo de reconocimiento y sus efectos para jerarquizar a las personas en relación con los beneficios de un orden social. Por lo tanto, la acumulación de capital moral es una vía para acceder a recursos y poder.

El concepto de capital moral también recoge la exigencia de analizar las disputas de significados morales sobre las personas y sus acciones en marcos contextuales específicos. El capital moral remite a los esquemas de percepción y apreciación que reconocen propiedades pertinentes como virtudes. Los usos sociales de los juicios y evaluaciones morales sacan de la indiferencia moral a las personas y sus actos para ponderarlos y valorizarlos. La acumulación de capital moral está ligada a la competencia por imponer esos esquemas de apreciación y evaluación; los desacuerdos y controversias sobre las virtudes valoradas en cada contexto son expresiones de esta dinámica conflictiva.

A continuación quisiera mostrar cómo este concepto cumple estos tres requisitos de una nueva sociología moral en un contexto específico: el mundo económico. 


\section{Dinero y capital moral}

La renovación de la nueva sociología económica en la década del ochenta tuvo como motor principal reparar en las redes sociales de la economía. Un concepto estaba en el núcleo de esta propuesta: el de confianza (Granovetter, 1973). Sin embargo, esta perspectiva no proponía una mirada alternativa a la acción económica, sino que mostraba cómo ella se "encrustaba" en tales redes de confianza. Trabajos posteriores, como los de Viviana Zelizer, ayudaron a pensar internamente una nueva noción de acción económica. La noción de capital moral no se encuentra en la periferia de las acciones económicas sino en su centro, define su naturaleza. En este sentido, mi propuesta se emparenta con las propuestas recientes de la sociología económica, donde se analiza el mundo económico desde las apuestas morales y éticas que se ponen en juego (Fourcade y Healy, 2007). ${ }^{3}$

En Ensayo sobre el don, Mauss sugiere que se piense la moneda de una manera que vale la pena traer a mi argumentación sobre la noción de capital moral. Mauss defiende la idea de que se puede considerar los bienes personales como monedas, no desprovistas de componentes morales para circular como medios de pago. En su texto, las monedas no son hostiles a la moral, para retomar una figura de Zelizer. El concepto de capital moral se ubica en esta perspectiva: pretende mostrar al dinero como un transporte de virtudes y valores morales en lógicas monetarias plurales (mercantiles y no mercantiles, formales e informales, familiares y barriales, políticas y religiosas, legales e ilegales).

El dinero pone a prueba (Boltanski y Thevenot, 1991) a las personas y sus vínculos sociales. La sociología moral del dinero que aquí presento analiza cómo éste circula o deja de circular, a la par que se prueban virtudes morales y se acumula ese capital que llamo moral. Pienso así cómo las jerarquías morales son definidas monetariamente. El dinero es un gran clasificador social, a través del cual se juzgan las virtudes y defectos que jerarquizan a las personas. El uso del dinero distribuye reconocimientos, guarda recuerdos, transportan virtudes, en definitiva, prueba a las personas.

Ser "pagador", "leal”, “cumplidor", "respetable”, "generoso", “trabajador" o "desleal", "incumplidor", "avaro" y "vago" constituyen juicios morales que las personas luchan para alcanzar e imponer y expresan los litigios por definir las jerarquías que habilitan o prohíben la circulación del dinero.

${ }^{3}$ El concepto de capital moral tiene un "aire de familia" con el de economía moral (en la versión clásica de E. P. Thompon o J. Scott, y en la actual de Didier Fassin). Para ver sus diferencias consúltese Wilkis (2014b). 
La sociología moral del dinero que ensayo intenta mostrar cómo se construyen jerarquías morales a través de dinámicas monetarias, mostrando así cómo éstas contribuyen a expresar y darle forma a concepciones del orden social.

En las páginas que siguen quisiera poner en perspectiva esta sociología moral en relación con las dinámicas del mundo popular y su nueva infraestructura monetaria.

¿Cómo la sociología moral del dinero invita a repensar la economía popular? ¿Por qué esta perspectiva es hoy necesaria frente a la configuración de una nueva infraestructura monetaria? ¿Cómo ayuda ella a comprender la vida colectiva a partir del solapamiento de jerarquías morales y monetarias?

\section{La economía popular desde la sociología moral del dinero}

Las etiquetas más usadas para nombrar a la economía popular suelen proponer una dimensión de análisis que define ese universo de prácticas y relaciones sociales. Por ejemplo, la categoría de pobreza le presta atención a la escasez. La categoría de la economía social hace lo suyo con la solidaridad. Si seguimos pasando revista por las diferentes categorías veremos que la informalidad se enfoca en la falta de regulación o la economía ilegal en el incumplimiento de normas del derecho penal. Sin embargo, la economía popular está atravesada por lógicas plurales que ninguna de estas etiquetas capta por sí sola. Podemos preguntarnos: ¿cómo analizar las ganancias en esta economía desde una categoría que sólo analiza la escasez? ¿Cómo las relaciones mercantiles desde aquella que acentúa la reciprocidad por fuera del mercado? ¿Cómo hacerlo con la competencia y el conflicto desde aquella que acentúa la solidaridad? Tampoco, a fuerza de acentuar una dimensión de análisis, logran mostrar conexiones y regularidades que atraviesa un mundo de prácticas y relaciones sociales plurales.

En un trabajo anterior (Wilkis, 2013) argumenté a favor de considerar el dinero en el mundo popular como una vía conceptual y metodológica para conectar los diferentes fragmentos de la vida social. También argumenté que la nueva infraestructura monetaria del mundo popular generaba las condiciones para esta propuesta, ya que el dinero se tornaba cada vez más central en la vida de personas, como Mary y su familia.

$\mathrm{Si}$, como lo sintetiza un estudio de las ciencias sociales en América Latina (Trindade, 2007), los desarrollos actuales han tendido a fragmentar el conocimiento social, una sociología del dinero podría ser una de las vías para restituir las conexiones entre esas partes. 
Bajo esta perspectiva, la sociología moral del dinero aquí presentada es, en primer lugar, una apuesta a reconstruir una pluralidad de dinámicas monetarias y sus conexiones que desbordan las etiquetas más usuales para nombrar la economía popular.

Encontramos estas dinámicas monetarias y morales en los circuitos informales, pero también formales, en los ilegales pero también en los de la economía social. Ser buen pagador, por ejemplo, es algo reconocido en todos estos circuitos y no es exclusivo de ninguno. Todos éstos pueden ser interpretados a través de las luchas de reconocimiento de virtudes conectadas a las dinámicas monetarias.

Hablar de capital moral es entender que se requiere ser reconocido por poseer ciertas virtudes para que se realice un préstamo o se participe en actividades que no están encuadradas en ninguna normativa legal. Poseer este capital es el derecho de entrada a ciertas transacciones económicas que de otra manera no se lograría. Los mercados ilegales son también espacios que requieren reconocimientos morales. Este reconocimiento (por ejemplo respetar los plazos de las deudas) debe ser mantenido permanentemente; el costo de perderlo es quedar afuera de transacciones económicas que pueden ser favorables y ventajosas. Obtenerlo puede dar varias ventajas en el mundo económico popular.

Esta perspectiva propone ver la continuidad de estas dinámicas en espacios tratados comúnmente como separados y de manera opuesta (mercantiles, no mercantiles, formales, informales, legales, ilegales, domésticos). La sociología moral del dinero, en este sentido, es una invitación a descifrar la vida económica popular como un espacio continuo donde las jerarquías morales son creadas y mantenidas monetariamente.

\section{Las sospechas del dinero}

Hay ciertas concepciones que ven al dinero como un mal, un elemento que distorsiona las virtudes humanas, que disuelve los lazos sociales, etc. Podemos ver estas concepciones en figuras tan opuestas como las de San Agustín o Marx (Bloch y Parry, 1989). Para referirse a estas cosmovisiones, Viviana Zelizer habla del dinero como un "ácido social". Por mi parte, en Wilkis (2013) propuse hablar de "las sospechas del dinero". Argumenté que estas sospechas tienen su fuente en que el dinero es algo que otorga independencia: siempre se puede convertir en otra cosa. Marcel Mauss (1971) pensaba que el dinero es un poder. Georg Simmel (1996) [1987] reflexionaba: el dinero es un medio de medios, no tiene fin su capacidad de transformarse. Creo 
que gran parte de las sospechas vienen de ahí: es un poder que no se puede controlar completamente y eso genera sospechas.

La hipótesis que presento es la siguiente: cuando más se estructura monetariamente el mundo popular, más está expuesto a ser juzgado a través del dinero sospechado.

Estas sospechas son cruciales para definir una posición subalterna. Cuando aparece el dinero, aparece la sospecha: ¿de dónde proviene?, ¿qué se hace con él?

El dinero sospechado muestra cómo el dinero que circula en el mundo popular carga estigmas y prejuicios; cómo el dinero lejos de ser neutral es un transporte de formas de impugnación simbólica muy recurrentes. La sociología moral del dinero saca a la luz esta relación entre dominación simbólica y dinero que pauta ciertas dinámicas que atraviesan la economía popular.

La nueva infraestructura monetaria del mundo reactualiza las "sospechas del dinero" en manos de los pobres. La monetización de la política social, la financiarización o la ampliación del consumo han desplegado un espacio monetario desde donde las clases populares se exponen a ser juzgadas moralmente.

El régimen de opiniones y sentimientos del dinero sospechado que se despliega junto a una nueva infraestructura monetaria del mundo popular toma la forma de una posición absoluta. Una representación discontinua que separa, por un lado, actos y personas morales; por otro lado, actos y personas inmorales.

Veamos cómo Mary nos transporta por este régimen de opiniones y sentimientos del dinero sospechado.

\section{a) Las sospechas del dinero de los programas sociales.}

Las hijas de Mary empezaban a cobrar unas becas para que fueran a la escuela. Este dinero se sumaba a otro tipo de transferencia condicionada provista por el Estado. Según datos oficiales del gobierno argentino, entre 2004 y 2013 se triplicó el porcentaje de los hogares más pobres que recibían asistencia monetaria (de $9.8 \%$ a $35.8 \%$ ); al mismo tiempo decreció el porcentaje que recibía ayuda en especie como alimentos, ropa, etc. (de $21.6 \%$ a $5.4 \%$ ) (Encuesta EPH, INDEC, 2004-2013).

La centralidad creciente del dinero público como parte de las políticas de asistencia lo convirtió en un transporte privilegiado de prejuicios y estigmas sobre estos sectores. Wilkis (2013) y Hornes (2013) muestran cómo en la Argentina sectores políticos, miembros de las clases medias pero también de 
las clases populares convirtieron este dinero en un artefacto de evaluación moral sobre los pobres; éstos empezaron a ser juzgados moralmente a través del dinero. Bajo esta pieza de dinero se transportan tanto la autoridad de juzgar como de condenar. Autoridad que asume una parte de la sociedad en relación con los pobres y el dinero que reciben por parte del Estado. Desde este punto de vista, el derecho a tener o no una protección social monetaria por parte de los más necesitados pasa a convertirse en tema de discusión y quienes opinan lo hacen con la potestad de juzgar los usos del dinero. Los juzgadores se convierten así en emprendedores morales (Becker, 2009 [1963]) a través del dinero público, y éste se vuelve dinero sospechado.

Cuando las transferencias condicionadas del dinero pautan el paradigma de las políticas sociales, resulta casi imprescindible considerar que los litigios sobre el dinero público expresan concepciones monetarias del orden social. ${ }^{4}$

\section{b) Las sospechas del dinero del consumo}

Así como Mary anhelaba comprar una nueva heladera con el plástico de su comadre, sus hijos compraban zapatillas o ropa con las tarjetas de las casas de indumentaria y algunos de sus vecinos pagaban créditos personales de las tantas agencias que abrieron cerca de Villa Olimpia en los últimos años. Muchos de ellos aprovechaban la oportunidad que una tienda les brindaba para adquirir muebles o electrodomésticos a plazos, bajo condiciones acordes a sus posibilidades de pago. Todos participaban en las nuevas conexiones entre la oferta del crédito y el consumo de las clases populares. En diciembre de 2009 organicé una encuesta sobre consumo y crédito entre estos sectores (Wilkis, 2014a). La descripción de los hogares según los bienes que se poseían detallaba que entre $70 \%$ y $100 \%$ de sus integrantes poseían teléfonos celulares, equipos de música, heladeras, lavarropas, televisores y reproductores de DVD. El papel del crédito marcaba la lógica de consumo: habían accedido a esos bienes por la obtención de créditos para televisores (44.2\%), reproductores de DVD (34.6\%), lavarropas (47.7\%), heladeras (66\%), equipos de música $(46.7 \%)$ y celulares $(52.2 \%)$.

La nueva infraestructura monetaria ha sido dinamizada tanto por las políticas públicas orientadas a mejorar los ingresos de los sectores de menos

${ }^{4}$ Hoy, estos litigios se han vuelto transnacionales. Los encontramos tanto en el conurbano bonaerense (Hornes, 2013), como en la ciudad brasileña de Porto Alegre (Eger, 2012), o en un pueblo de Yucatán al sur de México (Dapuez, 2011). Aquí, allá y en todas partes, el uso eficiente, delineado por los expertos en políticas sociales, choca con la moral de los receptores, que definen otras prioridades y movilizan otros sentidos del dinero y, por lo tanto, también del orden social. 
recursos como por las estrategias de las empresas para incorporar nuevos clientes luego de la crisis económica y social de 2001. Esta incorporación al consumo estuvo marcada también por sospechas con respecto al dinero. Figueiro (2013) analizó las percepciones negativas sobre el uso de teléfonos celulares o ropa deportiva de marca por parte de los jóvenes de las barriadas populares del gran Buenos Aires. La sospecha sobre este dinero - argumenta Figueiro - asoma a través del prisma moral de la irracionalidad que supone que personas con escasos recursos destinen sus ingresos a estos bienes.

\section{c) Las sospechas del dinero de los mercados populares}

La vida económica de Mary se insertaba en el mercado popular de La Salada. Esta dinámica no se basa únicamente en causas locales. Mary obtenía su ganancia de lo que algunos han denominado "globalización popular desde abajo" (Ribeiro, 2012). Los mercados populares constituyen nodos de densas redes comerciales por los que circulan productos (muchos de ellos, falsificaciones) con China como principal, pero no único, centro de producción. Roxana Pinheiro-Machado (2011) desglosó las cadenas globales de personas y bienes que anudan lugares y etnias entre China, Paraguay y Brasil. Sus conclusiones parecen proyectarse también hacia la feria gigante del conurbano sur (y a otras que se despliegan por Latinoamérica). En La Salada conviven bienes importados con los producidos localmente en talleres informales y clandestinos (Gaggo, 2012).

El tránsito de Mary por La Salada se conectaba con esta dinámica transnacional y con una jerarquía monetaria que se emplea para interpretar el mundo popular, también transnacional. La Unión Europea calificó a la feria como "el mercado ilegal más grande de América Latina". Los medios locales contribuyeron a esta definición. "Inmensa feria de lo trucho", "Feria de productos ilegales más grande de Latinoamérica", "Megaferia de productos truchos", "Pequeño polo de desarrollo ilegal", "Centro de ventas de mercadería falsificada más grande del país", "Meca de lo trucho", "El shopping de los pobres", "La Ciudad del Este del conurbano": así adjetivaban los diarios y los noticiarios argentinos, sin prestar importancia a cómo contribuyen a construir una visión parcializada del mundo popular. Estas categorías de clasificación y percepción condenan formas innobles y desjerarquizadas de participación en el mundo de la economía. Bajo estas categorías, las ganancias que se obtienen en estos mercados son siempre sospechosas.

Bajo la forma de litigios morales, el dinero presupone una lucha simbólica sobre el mundo popular. El dinero sospechado recoge una relación desigual 
de esta lucha: aquella capaz de representar el mundo popular desde la mirada parcial que acentúa la impugnación y la condena. Esta pieza de dinero es crucial para definir una posición subalterna frente a las maneras dominantes de definir virtudes como el prestigio, el esfuerzo, el mérito o la justicia. ${ }^{5}$

Si el punto de vista absoluto es una representación discontinua del mundo social (de un lado actos y personas morales, del otro lado actos y personas no morales), la sociología moral elabora una perspectiva completa capaz de unificar lo que estas representaciones separan. Pensar en estos términos permite tanto reflejar la arbitrariedad que existe cuando las personas experimentan de manera absoluta sus juicios y evaluaciones morales, como evitar atribuirle a un individuo, grupo o universo social el monopolio sobre los mismos.

Una sociología moral del dinero desestabiliza los juicios absolutos sobre el dinero sospechado y los reconstruye como puntos de vista entre puntos de vista. Frente a la representación discontinua devuelve una imagen más realista y concreta. Propone mostrar que no hay un valor absoluto del dinero tanto para condenarlo como para celebrarlo.

\section{Las piezas del dinero}

El dinero sospechado que tiende a dominar el régimen de opiniones y sentimientos sobre el dinero en mano de los pobres es una "pieza" de dinero entre otras. Sólo muestra la degradación o la condena. Pero vimos, con relación a Mary y su familia, que el dinero conecta a las personas a través de esperanzas, afectos, deseos, respeto, orgullo, odios y conflictos.

Desde esta perspectiva, el dinero resulta tan central como lo son las piezas en el armado de un rompecabezas. Así como éstas son múltiples, también lo son las opiniones y sentimientos del dinero. Completar el tablero del rompecabezas del mundo popular implica descubrir las piezas del dinero que lo componen: el dinero sospechado es una de ellas pero también, como vimos con Mary, hay otras.

${ }^{5}$ Como hemos observado en relación con el dinero público, el de la religión también transporta estigmas y acusaciones. Una parte de la sociedad se convierte en emprendedora moral y se arroga la potestad de juzgar a los sectores populares y sus usos del dinero. El dinero sospechado ha sido uno de los instrumentos para impugnar los procesos de transformación de la religiosidad popular. En Rio de Janeiro (Lima, 2008) o en Buenos Aires (Semán, 2000), las etnografías disponibles muestran el crecimiento de grupos como los pentecostales a la par de su condena monetaria. La perspectiva del dinero sospechado impugna las nuevas formas de religiosidad, acusándolas de contagiar el individualismo y la mercantilización de la fe que manipula a los pobres. 
En el relato etnográfico en torno a Mary y su familia se despliegan algunas piezas. La pieza del dinero prestado permite mostrar la centralidad de los procesos de endeudamiento y financiarización hoy día, el dinero militado, el lugar del dinero en la política popular, así como el dinero sacrificado, la relación entre religión y dinero. El dinero cuidado invita a comprender cómo las familias socializan a sus hijos en ciertas culturas monetarias. El dinero donado capta todo lo que se pone en juego cuando se transfiere el dinero hacia los pobres en calidad de ayuda o asistencia. El dinero ganado abre una mirada sobre las dinámicas de búsqueda de ganancia en el mundo popular.

Cada una de estas piezas circula siguiendo un régimen de opiniones y sentimientos del dinero específico, que impone una gramática de acumulación de capital moral específico, afirmando moralidades monetarias que ponen a prueba a las personas y sus vínculos sociales.

El dinero prestado, por caso, pone en juego esta moralidad a través de la prueba del crédito y la devolución de una deuda. Esta pieza no puede circular sin movilizar opiniones y sentimientos referidos a ese pago. Según el antropólogo Keith Hart (2000), una de las funciones esenciales del dinero consiste en recordar; las deudas son la evidencia más clara de esta propiedad del dinero. A través de las deudas las personas guardan recuerdos, la memoria se constituye monetariamente. Esto puede observase en un doble sentido. Las personas endeudadas con familiares hacían todo lo posible para pagar su deuda con tal de que su nombre no quede manchado hacia el futuro, con la memoria que se tendrá de ellos. Esta es una de las dimensiones más dramáticas del dinero prestado: el abismo frente a una memoria insoportable. Pagar o no una deuda, cómo y cuándo pagarla, son todos actos que van configurando un reconocimiento moral sobre ellos. Para muchas familias, preservar su capital moral consiste en evitar ser recordados como incumplidores.

El régimen de opiniones y sentidos del dinero prestado pone a prueba, también, el reconocimiento moral del préstamo ante situaciones de emergencia. El recuerdo monetariamente guardado es sobre aquellos que estuvieron presentes en los momentos difíciles, o por el contrario sobre aquellos que estuvieron ausentes ante la necesidad de un préstamo. La memoria del dinero prestado "atesora" gestos, personas, vínculos. Este tipo de memoria monetaria es una fuente de solidaridad social.

El dinero militado, por su parte, prueba a las personas y los vínculos políticos.

El dinero en el mundo de la política resulta incómodo. La oposición de Max Weber (1996 [1919]) entre quienes viven de la política y quienes viven para la política se puede interpretar como un reconocimiento de esa presencia incómoda del dinero. La reflexión de Weber implicó darle legitimidad a un uso 
subordinado y no jerarquizado del dinero: podían recibir pagos monetarios quienes ocuparan roles inferiores, pero no los dirigentes. Más allá de esta solución específica, el problema persiste: el dinero en el mundo político, ¿es legítimo?, ¿para quiénes?, ¿por qué?

En una investigación clásica sobre sociabilidad política en barrios populares, Street Corner Society, W. F. White (1973 [1943]) describe la circulación del dinero a partir de su menor valía para imponerse en los vínculos entre los líderes políticos y sus seguidores: al ser un medio despersonalizado de intercambio, carece de fuerza para mantener obligaciones morales. Esta interpretación se ajusta a una concepción del dinero moralmente débil. En cambio, una concepción moral fuerte del dinero en los vínculos políticos se plasma en el análisis de los litigios morales de la circulación (o no) del dinero militado. Las opiniones y sentimientos de esta pieza están conectados a las obligaciones que se forman a partir de las lealtades políticas. Las virtudes que se reconocen a través del dinero militado están asociadas a cumplir estas obligaciones.

El dinero sacrificado es aquella pieza que prueba a las personas y sus vínculos a través del sacrificio de su uso. Durante mi trabajo de campo en barriadas populares del gran Buenos Aires tropecé muchas veces con afirmaciones como éstas en boca de dirigentes sociales, políticos y religiosos: "yo siempre pongo plata de mi bolsillo", "yo no cobro nada".

Haciendo uso de las herramientas conceptuales de Bourdieu, Daniel Gaxie ha propuesto comprender los actos desinteresados de militantes políticos o voluntarios de organizaciones sociales asociándolos a situaciones específicas. Los universos militantes son "oficialmente — es decir, autorizados, legítimamente, públicamente y colectivamente- desinteresados" (Gaxie, 2005). Los militantes adoptan un registro desinteresado cuando se encuentran en estas situaciones; en cambio, cuando se alejan de ellas expresan en secreto móviles interesados. La desconfianza hacia los motivos asociados al desinterés implica comprenderlos bajo determinados límites espacio-temporales. Al analizarlos en el marco de las situaciones oficiales, el investigador puede controlar el encantamiento que sienten estos agentes por sus propios actos. Esta perspectiva está sujeta a una segunda cuestión relevante. El "compromiso oficialmente desinteresado" (Gaxie, 2005) es reconocido públicamente por los militantes; por lo tanto, el lenguaje y los actos asociados al desinterés son intencionales y deliberados.

Desde mi punto de vista, las equiparaciones entre desinterés/situación oficial y entre interés/situación no oficial corren el riesgo de naturalizarse. La perspectiva de la sociología moral del dinero sugiere tres cosas: 1) el dinero sacrificado porta un principio desinteresado, su régimen de opinio- 
nes y sentimientos es el anti-utilitarismo; 2) este reconocimiento no tiene limitaciones espacio-temporales, se encuentra tanto en situaciones oficiales como no oficiales; 3) tampoco se emprende siempre bajo una búsqueda intencional: habría que comprenderlo como parte de una regulación social, que las personas siguen, incluso, más allá de su voluntad.

El punto que plantea esta perspectiva, entonces, tiene menos que ver con la oposición interés/desinterés y más con las jerarquías entre piezas de dinero. En este sentido, la presencia del dinero sacrificado en el mundo de la política, o del dinero militado en el mundo de la religión, habla de las economías monetarias que regulan la tensión y subordinación entre las personas en estos espacios.

El dinero cuidado contiene una moralidad monetaria asociada al sostenimiento de la reproducción familiar. En Estados Unidos, Viviana Zelizer, quien había señalado el rol del dinero en la definición de los roles familiares (Zelizer, 1994), investigó la conexión entre la vida afectiva y las actividades económicas (2009 [2005]). En Francia, Florence Weber (2005) también analizó los lazos afectivos, morales y económicos de la vida familiar. Si lo que llamamos "familia" es en parte fruto de representaciones - como señalaba Pierre Bourdieu (1994) —, los usos del dinero recogen la pretensión de darle unidad simbólica a las relaciones entre padres e hijos.

Para volver a hacer visible esta unidad contradictoria, mezcla de sentimientos y reproducción económica, de solidaridad y relaciones de poder, tomo como guía el régimen de opiniones y sentimientos del dinero cuidado, que cumple el rol de unir la economía doméstica con los afectos. Los presupuestos de los hogares están compuestos por piezas de dinero heterogéneas. El presupuesto del hogar de Mary se componía de piezas como el dinero militado, ganado, militado, donado. Ella gestionaba las finanzas familiares, que se convertían en una arena de negociación de bienes económicos y estatus sociales. Esas piezas múltiples se debían organizar bajo el régimen de las opiniones y los sentimientos del dinero cuidado. La gestión financiera se desplegaba cada día como una micro-política monetaria doméstica. ${ }^{6}$

El dinero cuidado elucida una evidencia para todas las piezas: no se hallan al margen de las desigualdades de género. Su circulación arrastra obligaciones generizadas; por medio de ellas, se evalúa a los hombres y las mujeres. No por casualidad esta pieza pone la atención en el género femenino del dinero:

${ }^{6}$ En otros contextos se encuentra la misma evidencia (Guerrin, 2000; Absi, 2007): las mujeres en condiciones de vulnerabilidad comprometen el dinero que llega a sus manos en la reproducción familiar, asumiendo lo que Michèle Perrot denominaba un "matriarcado presupuestario". 
ya sea debido a las políticas sociales, que las convierten en destinatarias del dinero público, gracias a instituciones como las que otorgan microcréditos (que las definen como más confiables que los hombres), o debido a la gestión eficaz de las finanzas familiares. Las mujeres de las clases populares son evaluadas positivamente por la responsabilidad que muestran en el cuidado (afectivo y económico) de sus hogares.

El dinero en sus manos debía emplearse para garantizar la reproducción de la familia. Cualquier otro destino resultaría impugnado: transformaría el dinero cuidado en sospechado.

El dinero donado cifra la expectativa de proponer un medio para reparar una necesidad; sus opiniones y sentimientos están conectados a que el dinero cumpla con este destino. La economía popular contiene dinámicas plurales, que podemos reconstruir por medio de las piezas del dinero. El dinero donado nos traslada a una región de la economía popular; el prestado, el militado, el sacrificado, el cuidado, a otras. Su circulación suscita varias preguntas: ¿quiénes son los necesitados legítimos? ¿Quiénes pueden recibir dinero por ello? ¿Qué hacen con el dinero?

El dinero donado cifra una expectativa de integración: su circulación arrastra el símbolo de un modo de concebir una participación legítima en la vida social. No se mueve sin operar jerarquías morales entre quienes se ajustan a esta participación y quienes no lo hacen. Y, precisamente, por eso tampoco puede dejar de producir desigualdades de poder y de estatus, ya que la realidad social de esta pieza de dinero conecta a quienes se ubican mejor situados para juzgar y a aquellos otros obligados a ser juzgados. Las personas enuncian fundamentos sobre las razones por las que creen que alguien debe recibir dinero como ayuda. Al hacerlo expresan sus concepciones sobre el mérito, la compasión, la justicia, la desigualdad, la igualdad, las jerarquías sociales, la solidaridad. Por medio de estas evaluaciones manifiestan sus valores morales: al valorar monetariamente, dicen lo que piensan y sienten sobre la integración al orden social.

En Wilkis (2013) propusimos considerar el dinero público proveniente de los programas sociales como un dinero donado. Bajo esta pieza de dinero, se transportan tanto la autoridad de juzgar como de condenar. Autoridad que asume una parte de la sociedad en relación con los pobres y el dinero que reciben por parte del Estado. Desde este punto de vista, el derecho a tener o no una protección social monetaria por parte de los más necesitados pasa a convertirse en tema de discusión y quienes opinan lo hacen con la potestad de juzgar los usos del dinero. Los juzgadores se convierten así en emprendedores morales a través del dinero público, y éste se vuelve dinero donado. 
El dinero ganado, por último, pone en juego opiniones y sentimientos relativos a la moralidad de la ganancia. Cuando un alto porcentaje de la población obtiene sus ingresos en la economía informal, cuando las instituciones financieras formales disciplinan débilmente el acceso al dinero, conviene considerar —invita Jane Guyer (2004) — la heterogeneidad de las experiencias en que se produce la ganancia del dinero. Su propuesta deja atrás un modelo arquetípico - teórico o ideológico- de transacción mercantil para explorar las conexiones plurales entre dinero, ganancia y mercado.

Inspirado también en la sociología moral de los mercados de Viviana Zelizer (1979; 1985), el dinero ganado permite explorar el espacio mercantil popular como un espacio moral de la ganancia. Esta incursión expone gramáticas de legitimación, tolerancia e impugnación de la ganancia. Esta pieza ayuda a descifrar eslabones de la economía popular que, muchas veces, quedan opacados por la perspectiva de la sospecha. Frente a la centralidad que la perspectiva del dinero sospechado ocupa a la hora de condenar la ganancia popular, la sociología moral del dinero considera que la búsqueda de ganancias no se ofrece como un dato natural ni resulta igual en los diferentes sectores sociales. Su representación parcial implica una negación de la legitimidad popular de la ganancia, cuyo efecto es reforzar la condena a los sectores populares, dado que se impugnan los medios y las modalidades por los cuales muchos de ellos aspiran a una vida mejor. Estas aspiraciones riegan los mercados globalizados y locales que activan la economía popular.

\section{Las jerarquías del dinero}

Luiz Fernando Dias Duarte (2004), en sus trabajos en Brasil, ha repuesto la noción de jerarquía para interpretar las cosmologías populares. Pablo Semán (2006) ha retomado este argumento para explorar la religiosidad de los habitantes de barrios relegados del conurbano de Buenos Aires. Una variante puede proponerse desde la sociología moral del dinero. ${ }^{7}$

Como vimos, el dinero sospechado es una forma de imponer una jerarquía social monetariamente fundada. Pero como vemos ahora a través de las piezas del dinero, la realidad del mundo popular puede ser descifrada a través de las múltiples dinámicas monetarias y morales que conectan esferas de la vida social: la política, la religión, la familia, el mercado. Estas dinámicas están

\footnotetext{
${ }^{7}$ Los trabajos de Jane Guyer (2004) han ido en la dirección de mostrar el solapamiento de las dinámicas monetarias con las jerarquías sociales.
} 
atravesadas por procesos de jerarquización monetaria que otorgan poder y estatus a los grupos y las personas.

$\mathrm{Al}$ circular, las piezas del dinero arrastran un solapamiento de órdenes sociales y órdenes monetarios. Cada pieza es indescifrable fuera de una jerarquía monetaria que, a su vez, proyecta una jerarquía social. Entre ellas prima la competencia por el rango de las cosas y las personas.

Desde esta perspectiva, no conviene considerar el dinero como una variable independiente de un proceso que se quiere explicar: su crecimiento cuantitativo no da razón por sí mismo de su papel en la vida social. Si lo tratamos como un dato aislado, tendemos a verlo de manera homogénea, como si produjera los mismos efectos en contextos diferentes. En cambio, si consideramos que sus valoraciones dependen de una jerarquía, nos vemos obligados a reconstruir las conexiones y diferenciales de sus usos como piezas.

Por ejemplo, a través de la competencia entre el dinero militado y el dinero sacrificado que enfrenta y jerarquiza a quienes reciben dinero y quienes no para participar en organizaciones sociales, políticas y religiosas. También lo vemos cuando del dinero ganado se proyecta con una mayor jerarquía frente al prestado o al militado, asociándolo a una ética del esfuerzo laboral frente al estigma de la deuda o la condena moral del clientelismo político. El dinero donado suele proyectar el rango más bajo en la jerarquía monetaria $\mathrm{y}$, por lo tanto, en la jerarquía social. Como hemos visto, la preservación del dinero cuidado en la más alta jerarquía al interior de las familias permite que éste discipline todas las piezas de dinero que conforman los ingresos de los hogares. Ninguna pieza en sí conlleva un significado unívoco: su sentido y su valor dependen de su relación con las otras. Esto impide atribuirle un valor absoluto al dinero, tanto para condenarlo como para celebrarlo.

\section{Palabras finales}

Una nueva infraestructura monetaria está redefiniendo los mecanismos de integración y sujeción en el mundo popular. Una mutación que torna imprescindible una sociología moral del dinero. Esta fue la tesis central de mi argumento.

El concepto de capital moral funcionó como un puente para conectar la agenda de la emergente sociología moral con los desarrollos contemporáneos de la sociología del dinero. A través de esta articulación propuse una mirada sobre el mundo popular basada en las dinámicas de solapamiento entre jerarquías morales y monetarias. Argumenté en favor de los aportes que esta perspectiva ofrece a las interpretaciones más habituales de la economía 
popular y también a su necesidad en el contexto de una nueva infraestructura monetaria.

Si las miradas externas sobre las dinámicas monetarias del mundo popular suelen acentuar la sospecha sobre ellas, excluyendo criterios de virtud, mérito o justicia, una sociología moral del dinero desplaza esta representación parcial al analizar los heterogéneos regímenes de opiniones y sentimientos que definen las piezas del dinero y producen un espacio de jerarquías morales monetariamente fundado.

La reconstrucción de las múltiples piezas del dinero y sus jerarquías devuelve una imagen de continuidad de la vida popular y restituye una visión completa, más concreta y realista que la producida por quienes adoptan puntos de vista que se pretenden absolutos.

El don (Mauss, 1971) es una conexión social que oscila entre el desinterés y el interés, la sujeción y la autonomía. El dinero, como lo hemos visto en estas páginas, también asume una oscilación constante. Conecta a las personas a través de solidaridades y de jerarquías, de reconocimientos y de sospechas, de afecto y de dolor. Una sociología moral ayuda a comprender cómo la autonomía y la sujeción son dos caras (siempre) oscilantes del dinero.

Recibido: febrero de 2014

Revisado: octubre de 2014

Correspondencia: Paraná 145/5to piso/C.P 1017/Buenos Aires, correo electrónico: ariel.wilkis@gmail.com

\section{Bibliografía}

Absi, Pascale (2007), "Il ne faut pas mélanger les fortunes: travail, genre et revenuschez les commerçantes de Potosi", en V. Hernández, P. Ould-Ahmed, J. Papaily y P. Phélinas (dirs.), Turbulences monétaires et sociales. L'Amérique Latine dans une perspective comparée, París, L'Harmattan, pp. 53-73.

Barrios, Macarena (2011), "Prácticas financieras en torno al uso del crédito en la industria del retail en Chile", en J. Ossandon (org.), Destapando la caja negra: sociología de los créditos al consumo en Chile, Santiago, Universidad Diego Portales, pp. 113-136.

Becker, Howard (2009) [1963], Outsiders. Hacia una sociología de la desviación, Buenos Aires, Siglo XXI.

Blanc, Jerome (2009), "Usages de l'argent et pratiques monétaires", en P. Steiner y F. Vatin, Traité de sociologie économique, París, Presses Universitaries de France, pp. 649-688. 
Bloch, Maurice y Jonhatan Parry (1989), “Introduction”, en M. Bloch y J. Parry, Money and Morality of Exchange, Cambridge, Cambridge University Press, pp. 1-20.

Bohannan, Paul (1959), "The Impact of Money on an African Subsistence Economy", The Journal Economic History, vol. 19, pp. 491-503.

Boltanski, Luc y Laurent Thevenot (1991), De la justification: les économies de la grandeur, París, Gallimard.

Carruthers, Bruce y Laura Ariovich (2010), Money and Credit. A Sociological Approach, Polity, Cambridge.

Cravino, María Cristina (2007), Las villas de la ciudad: mercado e informalidad urbana, Buenos Aires, Universidad Nacional de General Sarmiento.

Cravino, María Cristina, J. del Río y J. Duarte (2009), "Magnitud y crecimiento de las villas y asentamientos en el Área Metropolitana de Buenos Aires en los últimos 25 años", extraído de sitio web de la Facultad de Arquitectura, Universidad de Buenos Aires, diciembre.

DaMatta, Roberto y Elena Soárez (1999), Águias, burros e borboletas: um estudo antropológico do jogo do bicho, Rio de Janeiro, Rocco.

Dapuez, Andrés (2011), "Promesas rituales y compromisos de libre mercado. Regímenes de futuro en un pueblo de Yucatán", Revista Cuicuilco, núm. 51, pp. 181202.

Duarte, Luiz Fernando Dias (2004), "Las tres configuraciones de la perturbación en Occidente y los nervios de las clases populares", Revista Apuntes de Investigación, núm. 9.

Dufy, Caroline y Florence Weber (2009) [2007], Más allá de la Gran División. Sociología, economía y etnografía, Buenos Aires, Antropofagia.

Eger, Talita (2012), "Silencio que fala alto: vozes masculinas inaudíveis as acoessistenciais no ámbito do bolsa familia", ponencia del XV Encontro de Ciências Sociais do Norte e Nordeste, Brasil, septiembre.

Fassin, Didier (ed.) (2012), A Companion to Moral Anthropology, Nueva York, Wiley-Blackwell.

Figueiro, Pablo (2013), Lógicas sociales del consumo. El gasto improductivo en un asentamiento del partido de San Martín, Buenos Aires, UNSAM/Edita.

Figueiro, Pablo (2012), “'Clientes' y jugadores: el fiado en una agencia de lotería”, ponencia de las VI Jornadas Estudios Sociales de la Economía, Centro de Estudios Sociales de la Economía, Buenos Aires, Universidad Nacional de General San Martín.

Fourcade, Marione y Kieran Healy (2007), "Moral Views of Market Society”, Annual Review of Sociology, vol. 33, pp. 285-311.

Gaggo, Verónica (2012), “La Salada: ¿un caso de globalización desde abajo?”, Revista Nueva Sociedad, núm. 241, pp. 63-79.

Gaxie, Daniel (2005), "Retribution du militantisme et paradoxes de l'action colective", Swiss Political Science Review, vol. 1, núm. 1, pp. 157-188.

Granovetter, Mark (1973), “The Strength of Weak Ties”, American Journal of Sociology, vol. 78, núm. 6, pp. 1360-1380.

Guerrin, Isabelle (2000), Pratiques monétaires et financières des femmes en situation 
de précarité. Entre autonomie et dépendance, Lyon, Université Lyon 2, tesis de doctorado.

Guyer, Jane (2004), Marginal Gains. Monetary Transactions in Atlantic Africa, Chicago, The University of Chicago Press.

Hakim, Catherine (2010), “Erotic Capital”, European Sociological Review, vol. 26, núm. 5, pp. 499-518.

Hart, Keith (2000), The Memory Bank, Londres, Profile Books.

Hitlin, Steven y Stephen Vaisey (eds.) (2010), Handbook of the Sociology of Morality, Nueva York, Springer.

Hornes, Martín (2013), Transferencias monetarias condicionadas (TMC): de los saberes expertos a los sentidos plurales del dinero, Buenos Aires, IDES-IDAES, tesis de maestría.

Kessler, Gabriel (2013), "Ilegalismos en tres tiempos", en R. Castel, G. Kessler, D. Merklen y N. Murard, Individuación, precariedad, inseguridad, Buenos Aires, Paidós, pp. 109-176.

Lavinas, Lena (2013), "21 st. Century Welfare”, New Left Review, núm. 84, pp. 5-40.

Lima, Diana Nogueira de Oliveira (2008), "Prosperidade na década de 1990: etnografia do compromisso de trabalho entre Deus e o fiel da Igreja Universal do Reino de Deus", Revista Dados, vol. 51, núm. 1, pp. 7-35.

Mauger, Gerard (2006), Les bandes, le milieu et la bohème populaire: études de sociologie de la déviance des jeunes des classes populaires (1975-2005), París, Belin.

Maurer, Bill (2006), "The Anthropology of Money”, Annual Review of Antrhopology, vol. 35, pp. 15-36.

Mauss, Marcel (2009), Ensayo sobre el don, Buenos Aires, Katz.

Mauss, Marcel (1971), "Los orígenes de la noción de moneda", en M. Mauss, Obras completas II, Barcelona, Barral.

Müller, Lúcia (2009), “'Então, eu fui à luta!': repensando as representações e práticas econômicas de grupos populares a partir de uma trajetória de ascensão social", Política \& Sociedade, vol. 8, núm. 15, pp. 145-171.

Neiburg, Federico (2011), "Imaginary Moneys and Public Numbers: Comparing the Haitian and Brazilian Space of Calculability", Coloquio Novas Perspectivas en Etnografia da Economia: Modalidades de Troca e do Cálculo Econômico, Rio de Janeiro, Museu Nacional, mayo.

Nelms, Taylor (2012), "Soberanía y solidaridad en las finanzas populares", Jornada Moneda, Finanzas y Distribución de la Riqueza, Buenos Aires, Centro de Estudios Sociales de la Economía, diciembre.

Ossandon, José (org.) (2011), Destapando la caja negra. Sociología de los créditos al consumo en Chile, Santiago, Universidad Diego Portales.

Pharo, Patrick (2004), Sociologie et morale, París, Gallimard.

Pinheiro-Machado, Roxana (2011), Made in China: (in)formalidade, Pirataria, e Redes Sociais na Rota China-Paraguai-Brasil, San Paulo, Hucitec.

Rabossi, Fernando (2011), "Meanings through Money", Coloquio Novas Perspectivas Emetnografia da Economia: Modalidades de Troca e do Cálculo Econômico, Rio de Janeiro, Museu Nacional, mayo. 
Ribeiro, Gustavo Lins (2012), "Globalization from Below and the non Hegemonic Word-System", en G. Mathews, G. Lins Ribeiro y C. Alba Vega, Globalization from Below: The World's Other Economy, Londres, Routdledge, pp. 221-236.

Semán, Pablo (2006), Bajo continuo. Exploraciones descentradas sobre cultura popular y masiva, Buenos Aires, Gorla.

Semán, Pablo (2000), "El pentecostalismo y la religiosidad de los sectores populares", en M. Svampa (comp.), Desde abajo. La transformación de las identidades sociales, Buenos Aires, Biblos, pp. 155-180.

Simmel, Georg (1996) [1987], Philosophie de l'argent, París, Presses Universitaires de France.

Trindade, Helgio (org.) (2007), Las ciencias sociales en América Latina en perspectiva comparada, México, Siglo XXI.

Villarreal, Magdalena (2009), Mujeres, finanzas sociales y violencia económica en zonas marginadas de Guadalajara, Guadalajara, CIESAS.

Weber, Florence (2005), Le sang, le nom, le quotidien. Une sociologie de la parenté pratique, París, Aux Lieux d'être.

Weber, Max (1996) [1919], "La política como vocación”, en M. Weber, El político y el Cientifico, Madrid, Alianza, pp. 81-179.

White, W. F. (1973) [1943], Street Corner Society, Chicago, The University of Chicago Press.

Wilkis, Ariel (2014a), "Sociología del crédito y economía de las clases populares", Revista Mexicana de Sociología, vol. 76, núm. 2, pp. 225-252.

Wilkis, Ariel (2014b), "Sobre el capital moral”, Revista Papeles de Trabajo, núm. 13. Wilkis, Ariel (2013), Las sospechas del dinero. Moral y economía en la vida popular, Buenos Aires, Paidós.

Zanotelli, Francesco (2005), "La identidad del dinero. Rituales económicos en un pueblo mestizo de Jalisco", Relaciones. Estudios de Historia y Sociedad, vol. 26, núm. 103, pp. 52-91.

Zelizer, Viviana (2009) [2005], Negociando la intimidad, Buenos Aires, FCE.

Zelizer, Viviana (1994), The Social Meaning of Money: Pin Money, Paychecks, Poor Relief, and Other Currencies, Nueva Jersey, Princeton University Press.

Zelizer, Viviana (1985), Pricing the Priceless Child: the Changing Social Value of Children, Nueva Jersey, Princeton University Press.

Zelizer, Viviana (1979), Moral and Markets: the Development of Life Insurance in the United States, Nueva York, Columbia University Press.

\section{Acerca del autor}

Ariel Wilkis es doctor en Sociología por la Escuela de Altos Estudios Sociales (París) y la Universidad de Buenos Aires. Se desempeña como investigador del CONICET. Es profesor regular de sociología de la Universidad Nacional de San Martín y la Universidad Nacional del Litoral. Sus áreas de interés 
son sociología y antropología del dinero y las finanzas. Dos de sus publicaciones recientes son, coeditado con Alexandre Roig, El laberinto de la moneda y las finanzas. La vida social de la economía, Buenos Aires, Biblos, 2015; y Las sospechas del dinero. Moral y economía en la vida popular, Buenos Aires, Paidós, 2013. 